\title{
BMJ Open Effects of exergames training on postural balance in patients who had a chronic stroke: study protocol for a randomised controlled trial
}

\author{
Nathalia Priscilla Oliveira Silva Bessa (D) , Bartolomeu Fagundes de Lima Filho, \\ Candice Simões Pimenta de Medeiros, Tatiana Souza Ribeiro (D), \\ Tânia Fernandes Campos, Fabrícia Azevêdo da Costa Cavalcanti
}

To cite: Bessa NPOS, Lima Filho BF, Medeiros CSP, et al. Effects of exergames training on postural balance in patients who had a chronic stroke: study protocol for a randomised controlled trial. BMJ Open 2020;10:e038593. doi:10.1136/ bmjopen-2020-038593

- Prepublication history for this paper is available online. To view these files, please visit the journal online (http://dx.doi org/10.1136/bmjopen-2020038593).

Received 16 March 2020 Revised 12 August 2020 Accepted 04 October 2020

Check for updates

(C) Author(s) (or their employer(s)) 2020. Re-use permitted under CC BY-NC. No commercial re-use. See rights and permissions. Published by BMJ.

Departament of Physical Therapy, Federal University of Rio Grande do Norte, Natal, Brazil

Correspondence to Nathalia Priscilla Oliveira Silva Bessa;

nathyzinhasilva@gmail.com

\section{ABSTRACT}

Introduction Exergames training, as an additional therapy to standard care, has been widely used for motor recovery after patients who had a stroke, and it is a valuable and positive tool in the rehabilitation of this population. This study describes a single-blind randomised clinical trial that will aim to investigate the effects of exergames training on postural balance in patients with chronic stroke.

Methods and analysis Forty-two individuals with chronic stroke ( $>6$ months), aged $20-75$ years, will be randomised into two groups: the experimental group, which will be subjected to an exergames protocol, and control group, which will undergo a kinesiotherapy protocol. Both protocols are based on postural balance. The intervention will consist of 40-minute sessions two times per week for 10 consecutive weeks. The volunteers will be evaluated before the treatment, at the end of the interventions and 8 weeks thereafter. The primary outcome will be postural balance (Berg Balance Scale, Functional Reach Test, Timed Up and Go test and Centre of Pressure variables) and secondary outcomes will include gait $(6 \mathrm{~m}$ timed walk and Kinovea Software), cortical activation patterns (electroencephalography Emotiv EPOC), functional independence (Functional Independence Measure), quality of life (Stroke-Specific Quality of Life Scale) and motivation (Intrinsic Motivation Inventory).

Ethics and dissemination This protocol was approved by the Ethics Committee of the Federal University of Rio Grande do Norte (number 3.434.350). The results of the study will be disseminated to participants through social networks and will be submitted to a peer-reviewed journal and scientific meetings.

Trial registration number Brazilian Registry of Clinical Trials (RBR-78v9hx).

\section{INTRODUCTION}

According to the WHO, cerebrovascular disease was the leading cause of death worldwide in 2016. Of those deaths, 5.78 million were directly attributed to stroke, making it the main non-communicable cause of death. ${ }^{1}$ In Brazil, stroke resulted in approximately 100000 deaths in $2014,{ }^{2}$ and data indicate that
Strengths and limitations of this study

- This study will explore objective data of postural balance and gait through the force platform and kinematic analysis.

- This study is among the few that use electroencephalography to assess brain activity in stroke individuals undergoing an experimental protocol with exergames.

- The results of this research can lead to improvements in the use of exergames for postural balance in stroke rehabilitation.

- This study should benefit participants not only in physical aspects but also in psychological and social aspects.

- Blinding of participants will be not possible because of the nature of the intervention.

approximately 568000 affected individuals suffer from severe disability, making stroke the leading cause of disability in adults. ${ }^{3}$

Following stroke, various aspects of balance function are altered, such as delay in regaining the ability to assume the standing posture, loss of balance, asymmetry between the right and left limbs, increased postural sway and decreased weight bearing on the affected side ${ }^{45}$ Postural balance is important for functional tasks such as sitting, sit-to-stand and walking. Dysfunction leads to alterations in weight distribution patterns, causing the paretic leg to take less load. ${ }^{6}$ These changes increase the risk of falling, cause difficulties in executing functional activities and cause reduction in performance of daily living activities, leading to a consequent reduction in social participation, which can aggravate the clinical situation. ${ }^{7}$

Underuse of the impaired limb results in suppression of the cortical representation of the affected limb and further inhibition of its 
use. $^{8}$ The existence of cortical neural resources specialised in capturing changes in postural stability, which have been detected by changes in electroencephalography (EEG), supports the idea that postural adjustments are not only due to muscle responses to disorders but also due to cortically controlled intentional movements that may be altered following stroke. ${ }^{9}$

One major component of stroke rehabilitation is exercise therapy, ${ }^{10}$ and motor skill learning is particularly attractive because practice-induced improvement of sensorimotor performance supports the development of new aptitudes, providing the flexibility to adapt to changing conditions. ${ }^{11}$

From this perspective, exergames training has been widely used in rehabilitation with the aim of improving sensorial, cognitive, psychological and motor function. ${ }^{12} 13$ They have been characterised as experiences that simulate a real environment in which the user can interact with the scenario created by the game through the involvement of multisensory aspects. ${ }^{14}$ Exergames applications have the potential to apply relevant concepts of neuroplasticity, such as repetition, intensity and taskoriented training of the paretic extremity, ${ }^{7}$ and may entrain several brain areas involved in motor planning and learning, thus leading to an enhanced motor performance in rehabilitation. ${ }^{121516}$

There are some evidences to suggest the effectiveness of exergames in improving upper limb function and balance as an additional therapy to standard care in patients who had a stroke. Therefore, therapy based on exergames is a valuable and positive tool for the rehabilitation of this population. ${ }^{1718}$

A meta-analysis by Lee $e t a l^{19}$ found moderate evidence to support the effect of exergames training on improved lower limb function, including balance and gait, to a similar degree as upper limb function in patients who had a chronic stroke, suggesting that this technique may be used as a complementary treatment method alongside traditional rehabilitation therapy. However, most of the studies in this meta-analysis increased the overall treatment time by adding exergames training to conventional treatment, which may be the reason for the observed outcomes. $^{19}$

Considering the above evidence, it is paramount to investigate the isolated effectiveness of exergames rehabilitation and its contributions to positive changes in postural balance in patients who had a stroke, as this may provide additional evidence for the rehabilitation process in this population. From this perspective, it is hypothesised that training based on exergames improves postural balance, cortical activation, functionality, quality of life and motivation of patients who had a chronic stroke.

The purpose of this study to investigate the effects of exergames training on postural balance in patients who had a chronic stroke and to explore changes in cortical activation patterns, functionality, quality of life and motivation.

\begin{tabular}{|c|c|c|c|c|c|}
\hline \multirow[b]{3}{*}{ TIMEPOINT } & \multicolumn{5}{|c|}{ STUDY PERIOD } \\
\hline & \multicolumn{2}{|c|}{ Pre-treatment } & \multirow{2}{*}{$\begin{array}{c}\text { Post-allocation } \\
t_{1 \text { to }} t_{10}\end{array}$} & \multicolumn{2}{|c|}{ Post-treatment } \\
\hline & $-t_{1}$ & 0 & & $t_{\text {post10 }}$ & $t_{18}$ \\
\hline ENROLMENT: & & & & & \\
\hline Eligibility screen & $x$ & & & & \\
\hline Informed consent & $x$ & & & & \\
\hline Allocation & & $x$ & & & \\
\hline INTERVENTIONS: & & & & & \\
\hline Control Group & & & & & \\
\hline $\begin{array}{r}\text { Experimental } \\
\text { Group }\end{array}$ & & & & & \\
\hline ASSESSMENTS: & & & & & \\
\hline $\begin{array}{r}\text { Postural balance } \\
\text { deficits }\end{array}$ & $\mathrm{x}$ & & & & \\
\hline Cognitive screening & $x$ & & & & \\
\hline Spasticity & $x$ & & & & \\
\hline Ability to walk & $\mathrm{x}$ & & & & \\
\hline Stroke severity & $\mathrm{x}$ & & & & \\
\hline $\begin{array}{r}\text { Clinical and } \\
\text { demographic data }\end{array}$ & & $x$ & & & \\
\hline $\begin{array}{r}\text { Cardiovascular } \\
\text { parameter variables }\end{array}$ & & $x$ & $x$ & $\mathrm{x}$ & $\mathrm{x}$ \\
\hline $\begin{array}{r}\text { Adverse symptoms, } \\
\text { perceived effort and } \\
\text { pain }\end{array}$ & & & $x$ & & \\
\hline Postural balance & & $x$ & & $\mathrm{x}$ & $\mathrm{x}$ \\
\hline $\begin{array}{c}\text { Gait speed and } \\
\text { kinematic analysis }\end{array}$ & & $x$ & & $\mathrm{x}$ & $\mathrm{x}$ \\
\hline $\begin{array}{r}\text { Cortical Activation } \\
\text { Patterns }\end{array}$ & & $x$ & & $\mathrm{x}$ & $\mathrm{x}$ \\
\hline $\begin{array}{r}\text { Functional } \\
\text { independence }\end{array}$ & & $x$ & & $x$ & $x$ \\
\hline Quality of life & & $x$ & & $x$ & $\mathrm{x}$ \\
\hline Motivation & & & & $\mathrm{x}$ & \\
\hline Adverse events & & & & & $\mathrm{x}$ \\
\hline
\end{tabular}

Figure 1 Schedule of enrolment, interventions and assessments. $t_{1}$, 1st week; $t_{10}, 10$ th week; $t_{\text {post10 }}$, post-training; $t_{18}, 18$ th week.

\section{METHODS AND ANALYSIS Design}

A single-blind randomised controlled clinical trial that follows the recommendations of the Standard Protocol Items: Recommendations for Interventional Trials ${ }^{20}$ will be carried out (figure 1). Participants will be randomised to receive the exergames protocol (experimental group $(\mathrm{EG})$ ) and kinesiotherapy protocol (control group (CG)) (figure 2).

\section{Participants}

The study population will consist of 42 patients who had a chronic stroke living in the city of Natal or nearby. A volunteer selection will be carried out at the stroke patient care centres in the city. The selection can also be carried out via spontaneous demand by the voluntary search of patients who had a stroke after project advertisement on social media. After this, the first telephone contact will be made to clarify any questions from the participants and the first screening for inclusion will be performed.

\section{Inclusion and exclusion criteria}

The participants will be selected according to the following criteria: (1) first episode of unilateral stroke (ischaemic or haemorrhagic); (2) postural balance deficits (Berg Balance Scale score $(B B S))<45)^{21}$; (3) injury 


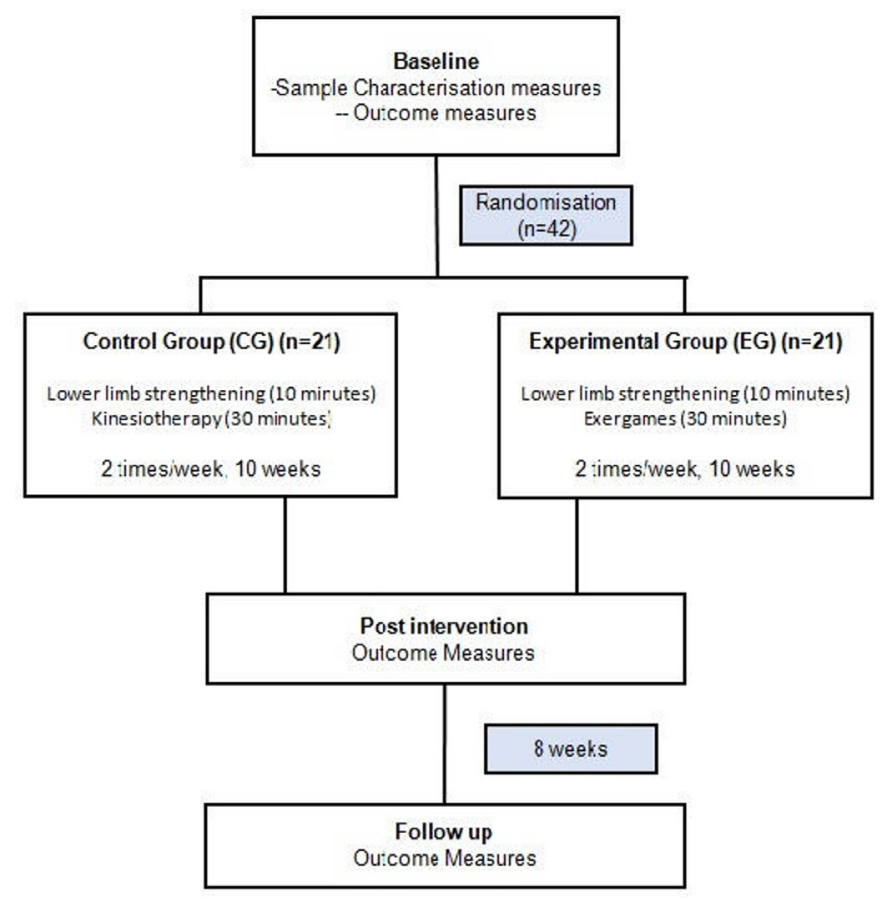

Figure 2 The schematic study design.

time $\geq 6$ months; (4) age between 20 and 75 years; (5) at maximum level 2 of the modified Ashworth Scale to assess the spasticity of the paretic lower limb ${ }^{22}$; (6) good cognitive status based on the Mini-Mental State Examination (MMSE) ( $\geq 19$ for illiterate, $\geq 24$ for literate $)^{23}$; (7) ability to walk without personal assistance indoors (Functional Ambulation Category (FAC)) scores $\geq 3)^{24}$; (8) clinically stable, with no history of epilepsy or seizures in the last 6 months; (9) not having signs of unilateral neglect or sensory or global aphasia as assessed by National Institute Health Stroke Scale (NIHSS)) ${ }^{25}$; (10) no uncorrected hearing and/or visual impairments; (11) not participating in a balance treatment protocol and (12) ability to understand and obey simple motor commands.

Exclusion criteria will include (1) presenting other clinical conditions affecting balance and (2) pregnancy.

\section{Sample size}

Using an online calculator ${ }^{26}$ and based on previous study values $(51.0 \pm 4.6$ and $46.2 \pm 5.7),{ }^{27}$ a total sample of 42 participants (21 in EG and 21 in CG) will be sufficient to detect a clinically important difference between the groups on the BBS. A statistical power of $80 \%$, an alpha of $5 \%$ and a loss rate of $10 \%$ were considered for the sample calculation.

\section{Randomisation and blinding}

A randomisation sequence will be generated by a computer $^{28}$ in 3 blocks of 12 participants and 1 block of 6 participants, allowing participants to be equally distributed between the two groups. This stage will be conducted by a researcher who is not involved in the study, they will keep the randomisation list confidential until the end of the study and will organise the allocation in sequentially numbered opaque envelopes. These envelopes will be sealed, and the randomisation sequence will be enforced using colour coding for the study groups (blue and red), that will correspond to the protocol that will be executed. The contents of each envelope will be revealed at the beginning of each patient's training by the study therapists responsible for the intervention to maintain allocation confidentiality. The same therapists involved in CG training will perform training in the EG. The researcher responsible for evaluations will be blinded to all intervention groups. The only variables that will be collected during the training will be evaluated by the study therapists (non-blind). Statistical analysis will be performed by a blind researcher who will treat the groups according to colour, and the equivalence between groups and colours will be revealed on completion of the statistical analysis. The main researcher will have access to the final trial dataset; this researcher will decide on terminating the trial. All information about participants will be confidentiality before, during and after the trial.

\section{Evaluation procedures}

The researchers will be trained before data collection procedures to ensure reliability of measurements, and the participants will be submitted to assessment using all the instruments mentioned below.

\section{Measures}

Sample characterisation measures

- Cognition: The MMSE is a validated instrument in Brazil used to assess cognitive function. The total score ranges from 0 to 30 points, and the higher the score, the better the cognitive ability. Values are interpreted according to educational status. Good cognitive status is considered with scores of 24 points higher for literate persons and 19 or higher for illiterate persons. ${ }^{23}$

- Ability to walk: This will be evaluated by the FAC, which is a sensitive and reliable instrument for gait evaluation in patients who had a stroke with hemiparesis ${ }^{24}$ and ranks the ability to walk according to the amount of physical support required for the task. The score can vary from 0 (unable to walk or needs the help of two therapists) to 5 (independent in locomotion).

- Spasticity: The modified Ashworth scale allows the subjective assessment of muscle tone and classifies the affected segments from 0 (normal tone) to 5 (rigid affected part). ${ }^{22}$

- Clinical and demographic data: Personal, anthropometric, demographic and pathological data (including, injury time, paretic side, stroke type), and clinical history (history of falls, physical therapy treatment and previous use of exergames) will be collected.

- Neurological impairment: NIHSS is a specific instrument to assess the severity of stroke via 10 items and has been reported to have excellent validity and reliability. ${ }^{25}$ 


\section{Outcome measures}

All outcome measures will be assessed in both intervention groups. The primary outcome measures considered in this study are as follows:

\section{Postural balance}

- BBS: It is a valid and reliable instrument for measuring both the static and dynamic aspects of balance in people after stroke. BBS scores range from 0 to 56 , and values below 45 points are predictive of falls, indicating a significant change in balance. ${ }^{21}{ }^{29}$ In the present study, test scores with the paretic limb positioned behind will be used in item 13 and unipodal support over the paretic limb will be used in item 14, minimising the ceiling effect in individuals with better balance. ${ }^{30}$

- Functional Reach Test: It assesses a patient's stability by measuring the maximum forward distance an individual can reach while standing in a fixed position. It is widely used to identify the risk of falling. ${ }^{31}$ Displacements $<15 \mathrm{~cm}$ indicate patient fragility and risk of falls. $^{32}$

- Timed Up and Go test: It is a valid instrument for assessing mobility and functional balance involving power, speed and agility. ${ }^{33}$ Performing the test within $10 \mathrm{~s}$ is considered normal for healthy, independent adults without the risk of falls. Values from $11 \mathrm{~s}$ to $20 \mathrm{~s}$ are expected for disabled or frail elderly people with partial independence and a low risk of falls. Values $>20$ s suggest significant physical mobility deficits and risk of falls. ${ }^{34}$

- Centre of Pressure (CoP) variables: Data for total displacement, anteroposterior and midlateral velocity of the CoP will be assessed using the gold standard equipment for balance assessment, the force platform (FP). ${ }^{35}$ The Bertec model 4060 connected to an external amplifier (Bertec AM651X) will be used.

The secondary outcome measures considered in this study are as follows:

\section{Cortical activation pattern}

Alpha and beta waves will be evaluated based on their relationship with the motor learning process, ${ }^{36}$ using the Emotiv EPOC portable 14 sensor EEG device, a gyroscope capable of detecting changes in the movement performed.

\section{Gait kinematic analysis}

The spatiotemporal and angular gait variables will be evaluated using the 6-metre timed walk test (6MTW) and Kinovea software.

- 6MTW: It is a valid and reliable test for the assessment of the walking ability of patients who had a stroke. ${ }^{37}$ Gait speed should be self-selected and considered comfortable and usual for the participant. Studies show variation in mean habitual speed (0.45-0.78 $\mathrm{m} / \mathrm{s}$ ) of gait in individuals with hemiparesis. 3839
- Software Kinovea: Kinematic evaluation will be performed during gait video capture (6MTW) using the Sony DCR-DVD850 digital camera, $02.7 / 6.7 \mathrm{~cm}$ LCD (liquid crystal display) screen and $60 \times$ optical zoom. Data will later be exported to Kinovea V.0.8.15 software for paretic lower limb angle and gait speed analysis. This is a public domain video editing and analysis software that is valid, reliable and capable of accurately measuring distances up to $5 \mathrm{~m}$ from the object. $^{40}$

\section{Functional independence}

The Functional Independence Measure (FIM) scale is used because of its reliability, validity, precision and feasibility criteria. It is composed of 18 items, including motor and cognitive items. Here the patient's answers are valued from 1 (total dependent) to 7 (complete independence), and the total punctuation ranges between 18 and 126. For this research, the FIM will be applied exclusively to the motor items, limiting the minimum score to 13 and the maximum to 91 points. ${ }^{41}$

\section{Quality of life}

Quality of life perception will be assessed through a quality-of-life assessment scale for stroke (Stroke-Specific Quality of Life Scale). It is valid and reliable in assessing the quality of life after stroke in the Brazilian population and has 49 items distributed over 12 domains. ${ }^{42}$

\section{Motivation}

The Intrinsic Motivation Inventory is a multidimensional measurement with six subscales used to assess the subjective experiences of participants when developing an activity and attends to the reliability and validity criteria. According to the inventory, instruction participants ranked their agreement with each statement on a Likert scale of 1 ('not at all true') to 7 ('very true'). ${ }^{43}$

\section{Participant monitoring measures}

Participants will be monitored during interventions using the following measures:

- Cardiovascular parameter variables: heart rate (HR) will be checked using a portable oximeter and blood pressure using a sphygmomanometer (Visomat Comfort III, Incoterm, São Paulo, Brazil) on the nonparetic arm.

- Adverse symptoms, perceived effort and pain: information regarding headache, vomiting and dizziness will be collected. Quantification of perceived effort and pain will be used as indicators to monitor exercise tolerance through the CR-10 (Category-Ratio Scale) Borg Scale ${ }^{44}$ modified by Foster et al. ${ }^{45}$

\section{Adverse events}

Additional information such as hospitalisations, falls, out-of-routine medical consultation, medication change, new diagnosis and the presence of adverse events will be collected during the follow-up. 
Table 1 Lower limb strengthening exercises

\begin{tabular}{|c|c|c|c|}
\hline Exercise & Evolution & Materials used & Sets \\
\hline 1. Get up and sit on a chair & Surface change & $\begin{array}{l}1 \text { or } 2 \text { mats to create an unstable } \\
\text { surface }(\mathrm{H}: 3 \times \mathrm{W}: 43 \times \mathrm{L}: 93 \mathrm{~cm})\end{array}$ & $\begin{array}{l}2 \text { sets of } 60 \mathrm{~s} \\
\text { with } 30 \mathrm{~s} \text { of rest }\end{array}$ \\
\hline 2. Go up and down steps & Increase the step height; add weight & Larger step and $1 \mathrm{~kg}$ shin pad & \\
\hline 3. Strengthening of hip extensors & Add weight & $1 \mathrm{~kg}$ and $2 \mathrm{~kg}$ shin pad & \\
\hline 4. Tiptoe rise & Add weight & $1 \mathrm{~kg}$ and $2 \mathrm{~kg}$ shin pad & \\
\hline
\end{tabular}

Source: Adapted from Allet et al. ${ }^{47}$

\section{Interventions}

The protocols in both groups will be performed individually through 40-minute sessions two times per week for 10 weeks (total of 20 sessions), totalling 13 hours of intervention. ${ }^{12} 1746$ The same outcome measures and motivation will be collected again at the end of the interventions (post-training) and after 8 weeks of the end of the interventions (follow-up). All participants will be instructed not to perform any other physical activity that works on body balance during the study period.

During each session, absences, manifestations of adverse symptoms and occurrence of imbalance and/or falls will be recorded. Interventional modifications will be performed according to the patient's level of adaptation involving optimisation of time or number of repetitions and/or rest time enlargement, and all will be registered.

Both groups will begin their protocols with adapted lower limb strength training for $10 \mathrm{~min}^{47} 48$ as described in table 1. Each exercise should be performed with respect to the patient's level of adaptation and evolution will occur in the 6 th and 13 th sessions using the materials described.

\section{Control group}

Participants in the CG will receive a kinesiotherapy protocol (30 min) (table 2), focusing on balance based on previous studies and that promotes stimuli similar to the EG, selected so they demand identical motor sensors in both intervention environments, real and virtual. ${ }^{47-50}$ Two progressions will happen, in the 6th and 13th sessions.

\section{Experimental group}

Participants in the EG will receive seven Wii Fit Plus exergames on the Nintendo Wii (30 min) (table 3). This will use the Wii Balance Board accessory, a multimedia projector and the Wii Remote Controller. Initially, participants will have a moment to adapt to Nintendo Wii and its components. It is expected that the participants in this group will be able to deal satisfactorily with the games used in the protocol after adaptation. Otherwise, they will enter the non-adherence criteria.

The games were pre-established with focus on balance, and demands similar to that of the kinesiotherapy protocol: saccadic stimulation, visuovestibular cephalic movement, proprioceptive stimulus, dynamic balance training, static gait, ankle and hip strategies, fine CoP control, stimulus optokinetic, double task (motor) and

\begin{tabular}{|c|c|c|c|}
\hline Exercise & Evolution & Materials used & Sets* \\
\hline 1. Gait training on a stable surface & $\begin{array}{l}\text { Gait training on an unstable surface } \\
\text { using mats; addition of shin pads } \\
\text { of } 1 \mathrm{~kg}\end{array}$ & $\begin{array}{l}\text { Mat and } 1 \mathrm{~kg} \\
\text { shin pads } \dagger\end{array}$ & 2 sets of $3 \mathrm{~min}$ \\
\hline 2. Laterolateral weight transfer and discharge & $\begin{array}{l}\text { Addition of } 1 \text { and } 2 \text { mats, } \\
\text { respectively }\end{array}$ & Mat & 3 sets of $60 \mathrm{~s}$ \\
\hline 3. Anteroposterior weight transfer and discharge & $\begin{array}{l}\text { Addition of } 1 \text { and } 2 \text { mats, } \\
\text { respectively }\end{array}$ & Mat & 3 sets of $60 s$ \\
\hline 4. Laterolateral cephalic movement with eyes open & $\begin{array}{l}\text { Same movement with eyes closed. } \\
\text { Added an exercise mat }\end{array}$ & Mat & 3 sets of $60 s$ \\
\hline 5. Anteroposterior cephalic movement with eyes open & $\begin{array}{l}\text { Same movement with eyes closed. } \\
\text { Added an exercise mat }\end{array}$ & Mat & 3 sets of $60 s$ \\
\hline 6. Dissociation of scapular and pelvic girdles & $\begin{array}{l}\text { Addition of } 1 \text { and } 2 \text { mats, } \\
\text { respectively }\end{array}$ & Mat & 3 sets of $2 \mathrm{~min}$ \\
\hline
\end{tabular}

Source: Adapted from Nascimento et $a{ }^{49}$; Soares and Sachelli ${ }^{48}$; Allet et $a l^{47}$ and Ribeiro et al. ${ }^{50}$

${ }^{*}$ For each series performed, the participant will be entitled to $30 \mathrm{~s}$ of rest.

†The mats (height: $3 \times$ width: $43 \times$ length: $93 \mathrm{~cm}$ ) will be used to create an unstable surface 


\begin{tabular}{|c|c|c|}
\hline Game & Description & Progression \\
\hline 1. Free Run & Control in patient's pocket 'marching' on firm surface & $\begin{array}{l}\text { Addition of } 1 \text { and } 2 \text { mats, } \\
\text { respectively* }\end{array}$ \\
\hline 2. Soccer Heading & $\begin{array}{l}\text { On WBB; performs anteroposterior and laterolateral weight transfer to virtually } \\
\text { 'hit' the head on the ball, with an attempt of } 180 \mathrm{~s} \text { and a throw of } 80 \text { balls }\end{array}$ & $\begin{array}{l}\text { Addition of } 1 \text { and } 2 \text { mats, } \\
\text { respectively }\end{array}$ \\
\hline 3. Pinguim Slide & $\begin{array}{l}\text { On WBB; performs laterolateral weight transfer in order to 'catch' the largest } \\
\text { number of fish, with three attempts of } 60 \mathrm{~s}\end{array}$ & $\begin{array}{l}\text { Addition of } 1 \text { and } 2 \text { mats, } \\
\text { respectively }\end{array}$ \\
\hline 4. Ski Slalom & $\begin{array}{l}\text { On WBB; performs laterolateral weight transfer for the purpose of deflecting } \\
\text { obstacles, and anteroposterior weight transfers to control speed while skiing } \\
\text { on the mountain, with three } 60 \mathrm{~s} \text { attempts }\end{array}$ & $\begin{array}{l}\text { Addition of } 1 \text { and } 2 \text { mats, } \\
\text { respectively }\end{array}$ \\
\hline 5. Table Tilt & $\begin{array}{l}\text { On WBB; performs small laterolateral and anteroposterior displacements as } \\
\text { a simulation of an unstable board to place the balls inside holes, with three } \\
\text { attempts of initial } 30 \mathrm{~s} \text {. You gain } 20 \text { s every one level you reach so that you do } \\
\text { not exceed } 180 \mathrm{~s}\end{array}$ & $\begin{array}{l}\text { Addition of } 1 \text { and } 2 \text { mats, } \\
\text { respectively }\end{array}$ \\
\hline 6. Free Steps & Up and down WBB, alternating feet with eyes open for $180 \mathrm{~s}$ & $\begin{array}{l}\text { Addition of weights } \\
\text { of } 1 \mathrm{~kg} \text { and } 2 \mathrm{~kg} \text {, } \\
\text { respectively }\end{array}$ \\
\hline 7. Balance Bubble & $\begin{array}{l}\text { On WBB; performs laterolateral and anteroposterior body displacement } \\
\text { without the bubble touching the banks of the virtual river for } 180 \mathrm{~s}\end{array}$ & $\begin{array}{l}\text { Addition of } 1 \text { and } 2 \text { mats, } \\
\text { respectively }\end{array}$ \\
\hline
\end{tabular}

Each game will be executed for $3 \mathrm{~min}$ with a rest interval of approximately $1 \mathrm{~min}$.

${ }^{*}$ The mats (height: $3 \times$ width: $43 \times$ length: $93 \mathrm{~cm}$ ) will be used to create an unstable surface. WBB, Wii Balance Board.

motor coordination. ${ }^{51-53}$ All scores obtained in games will be noted. Progression will occur on adaptation of the patient, two evolutions will occur, in the 6th and 13th sessions.

\section{Adherence}

Participants will be contacted by telephone to confirm assessment and training sessions to avoid sample loss. Strategies to improve adherence include making up for missed sessions and interventions of motivated professionals. Regardless of the protocol, the criteria for nonadherence will be considered as follows: (1) absence $>30 \%$ of the intervention, consecutively and without make-up sessions; (2) presenting persistent pain or severe discomfort (headache, vomiting, dizziness, etc), which prevents continuity in performing the proposed protocol in future sessions (or both); (3) presenting haemodynamic instability: decompensation of systemic arterial pressure (systolic and diastolic values $>200 \mathrm{~mm} \mathrm{Hg}$ and $110 \mathrm{~mm}$ $\mathrm{Hg}$, respectively $)^{54}$ and $\mathrm{HR}$ above the submaximal values allowed during the training maintained even after pauses, calculated by means of the formula $\left(\mathrm{HR}_{\mathrm{sub}}=0.75 \times(220-\right.$ age $)^{55}$ ) and (4) those who did not adapt to the proposed intervention.

\section{Data acquisition}

For data collection of the CoP variables, six static balance tests will be performed on the FP based on their complexity variation and common use in the literature $^{5657}$ : bipodal support on a stable surface with eyes open and eyes closed for $30 \mathrm{~s}$ each; unipodal support of paretic limbs on a stable surface with eyes open and eyes closed for $30 \mathrm{~s}$ each; unipodal support of non-paretic limb on a stable surface with eyes open and eyes closed for $10 \mathrm{~s}$ each. The distance between the patients' feet will be standardised $^{51}$ and in unipodal support tasks, the contralateral knee may be slightly flexed and there may be no contact between the raised and support legs. Each test can have one successful attempt and a maximum of three unsuccessful attempts. The attempt is considered invalid if the participant moves their support leg or touches the floor with the contralateral leg. ${ }^{58}$

For gait analysis during 6MTW, the camera will be positioned perpendicular to the plane of motion, at a height of $1 \mathrm{~m}$ and $3 \mathrm{~m}$ away from the subject to capture the gait pattern of the hemiparetic side, and will be considered as a complete gait cycle. Markers will be placed on the main bone references of the paretic lower limb (greater trochanter of the femur, lateral tibial condyle, lateral fibular malleolus, fifth metatarsal head and lateral calcaneal bone tuberosity) for further analysis.

For encephalographic recording during the FP static balance and walking tests, the Emotiv EPOC headset will be positioned on the user's head according to the international placement in the 10-20 positioning system following the manufacturer's specifications. ${ }^{59}$

\section{Data processing}

The Bertec Model 4060 platform will be synchronised with Qualisys Motion Capture Systems (Qualisys Medical AB, 41113 Gothenburg, Sweden), and through that system software, Qualisys Track Manager, data for CoP will be collected and converted to MATLAB compatible files 
(Mathworks, Natick, Rhode Island, USA). The sampling rate will be $40 \mathrm{~Hz}$, and a Butterworth bandpass filter with a cut-off frequency of $15 \mathrm{~Hz}$ will be applied to eliminate noise contamination.

For kinematic analysis, the videos will be converted to an Audio Video Interleave file extension and exported to Kinovea software. The hip, knee and dorsiflexion flexion angles will be evaluated in the middle oscillatory phase of gait, using the following joints: hip, tibiofemoral metatarsophalangeal and calcaneal. Emotiv EPOC data processing will follow the model used by Oliveira et al. ${ }^{60}$ The encephalographic recording will take place during gait and static balance tests, using $10 \mathrm{~s}$ of single-leg support activity and a central $10 \mathrm{~s}$ cutout in bipodal support activities.

\section{Statistical analysis}

The SPSS V.21.0 software programme will be used, and a significance level of $5 \%$ and $95 \%$ CI will be implemented for all statistical analyses. A descriptive analysis of the sample characterisation variables will be performed through central tendency and dispersion measures.

Normality tests (Kolmogorov-Smirnov) will be used for outcomes and will be compared between groups within each training session by using intergroup comparisons, $\mathrm{t}$ tests for independent samples, or Mann-Whitney U tests. A mixed analysis of variance with repeated measures will be used to compare values and variations of outcome measures, comparing values between groups and between baseline, post-training and follow-up assessments.

The effect size will be calculated using GPower V.3.1.9.3 (University of Dusseldorf, Kiel, Germany). Cohen's d will be used to calculate the effect size between the control and the EG, and the partial $\eta^{2}$ for intragroup analyses. ${ }^{61}$ Intention-to-treat analysis will be performed for dropout data, considering the last data obtained from the participant.

\section{Risk of bias and study limitation}

The present study has a low risk of selection bias due to randomisation and concealment of the allocation of participants; low risk of detection bias as the outcome assessor will be blind; high risk of performance bias because the participants will not be blind to the proposed therapies; reporting and attrition biases do not apply because it is a protocol study. ${ }^{62}$

The proposed follow-up time ( 8 weeks) can be considered a potential (minor) study limitation; it is not verified whether motor and neurophysiological changes resulting from the proposed intervention will be maintained over a long term (1 year). However, it is suggested that the effect of treatment with Nintendo Wii can be maintained for at least 2 months after the intervention, with improvements in motor recovery.

\section{Patient and public involvement}

Patients were not involved in the design of this trial, establishing the research question, or developing recruitment procedures. At the end of the study, the results will be reported to the participants in the form of a lecture, showing the effects found in the studied variables. The results of the study will be disseminated to participants through social networks and will be submitted to a peerreviewed journal and scientific meetings.

\section{Ethics and dissemination}

This research was approved by the Research Ethics Committee of the Federal University of Rio Grande do Norte, with protocol number 3.434.350 on 3 July 2019. Participants will be informed of the study objectives, its risks and benefits and when eligible for inclusion, if they agree to participate, must sign the informed consent before the study begins. They will be free to abandon the study at any time without the obligation to give any explanation.

There will be prior contact with individuals through social networks, when all information about the study will be presented as well as the Resolution No 466/2012 of the Brazilian National Health Council of 2012, which provides guidelines and standards for research involving human participants. In case any negative effects occur, participants who suffer harm from trial participation will receive physical assistance according to the injury. The study results will be disseminated to participants through social networks and will be submitted to peer-reviewed journals and scientific meetings.

\section{Protocol amendments}

Protocol amendments will be documented with descriptions of the change and the date of the change.

\section{Study status}

Subject recruitment is underway, started in November 2019, but the first inclusion was in January 2020. To date, eight patients were enrolled in the study. The recruitment period spans till January 2021. The goal is to include 21 patients per treatment group, each patient completing the rehabilitation programme and evaluation before and after, and 8 weeks later.

\section{Twitter Bartolomeu Fagundes de Lima Filho @bartofagundes}

Contributors NPOSB led the study design and wrote the manuscript. BFdLF, CSPdM, TSR, TFC and FAdCC have made substantial contributions to the design of the study. NPOSB and BFdLF participate in participants' recruitment and data collection. All authors reviewed and approved the manuscript.

Funding This study was financed in part by the Coordenação de Aperfeiçoamento de Pessoal de Nível Superior-Brasil (CAPES)—Doctorate's degree scholarship, Finance Code 001.

\section{Competing interests None declared.}

Patient and public involvement Patients and/or the public were not involved in the design, or conduct, or reporting, or dissemination plans of this research.

Patient consent for publication Not required.

Provenance and peer review Not commissioned; externally peer reviewed.

Open access This is an open access article distributed in accordance with the Creative Commons Attribution Non Commercial (CC BY-NC 4.0) license, which permits others to distribute, remix, adapt, build upon this work non-commercially, and license their derivative works on different terms, provided the original work is properly cited, appropriate credit is given, any changes made indicated, and the use is non-commercial. See: http://creativecommons.org/licenses/by-nc/4.0/. 


\section{ORCID iDs}

Nathalia Priscilla Oliveira Silva Bessa http://orcid.org/0000-0002-3160-8102

Tatiana Souza Ribeiro http://orcid.org/0000-0002-9611-1076

\section{REFERENCES}

1 World Health Organization. Global health estimates 2016: deaths by cause, age, sex, by country and by region, 2000-2016, 2018. Available: https://www.who.int/healthinfo/global_burden_disease/ estimates/en/index1.html [Accessed 22 Nov 2019].

2 Brasil. Óbitos p/ Ocorrência segundo Causa - CID-BR-10. In: In: Informações de Saúde: Estatísticas vitais: mortalidade: Mortalidade geral - 1996 a 2014: Região e Unidade da Federação. Ministério da Saúde, 2014. http://www.datasus.gov.br. (Accessed 22 Nov 2019).

3 Bensenor IM, Goulart AC, Szwarcwald CL, et al. Prevalence of stroke and associated disability in Brazil: National Health Survey--2013. Arq Neuropsiquiatr 2015;73:746-50.

4 Dickstein R, Abulaffio N. Postural sway of the affected and nonaffected pelvis and leg in stance of hemiparetic patients. Arch Phys Med Rehabil 2000;81:364-7.

5 de Haart M, Geurts AC, Dault MC, et al. Restoration of weightshifting capacity in patients with postacute stroke: a rehabilitation cohort study. Arch Phys Med Rehabil 2005;86:755-62.

6 Lee C-H, Kim Y, Lee B-H. Augmented reality-based postural control training improves gait function in patients with stroke: randomized controlled trial. Hong Kong Physiother J 2014;32:51-7.

7 Langhorne P, Coupar F, Pollock A. Motor recovery after stroke: a systematic review. Lancet Neurol 2009;8:741-54.

8 Barato G, Fernandes T, Pacheco M. Cortical plasticity and neurological physical therapy techniques in Neurolmage optic. Rev Neurocienc 2009;17:342-8.

9 Slobounov S, Hallett M, Stanhope S, et al. Role of cerebral cortex in human postural control: an EEG study. Clin Neurophysiol 2005;116:315-23.

10 Kleim JA, Jones TA. Principles of experience-dependent neural plasticity: implications for rehabilitation after brain damage. J Speech Lang Hear Res 2008;51:225-39.

11 Lefebvre S, Laloux P, Peeters A, et al. Dual-tDCS enhances online motor skill learning and long-term retention in chronic stroke patients. Front Hum Neurosci 2012;6:343.

12 Saposnik G, Cohen LG, Mamdani M, et al. Efficacy and safety of non-immersive virtual reality exercising in stroke rehabilitation (EVREST): a randomised, multicentre, single-blind, controlled trial. Lancet Neurol 2016;15:1019-27.

13 Park D-S, Lee D-G, Lee K, et al. Effects of virtual reality training using Xbox Kinect on motor function in stroke survivors: a preliminary study. J Stroke Cerebrovasc Dis 2017;26:2313-9.

14 Peñasco-Martín B, Reyes-Guzmán A, Gil-Agudo A, et al. Aplicación de la realidad virtual en los aspectos motores de la neurorrehabilitación. Rev Neurol 2010;51:481-8.

15 Calabrò RS, Naro A, Russo M, et al. The role of virtual reality in improving motor performance as revealed by EEG: a randomized clinical trial. J Neuroeng Rehabil 2017;14:53.

16 Rohrbach N, Chicklis E, Levac DE. What is the impact of user affect on motor learning in virtual environments after stroke? A scoping review. J Neuroeng Rehabil 2019;16:79.

17 Laver KE, Lange B, George S, et al. Virtual reality for stroke rehabilitation. Cochrane Database Syst Rev 2017;11:CD008349.

18 Cano Porras D, Siemonsma P, Inzelberg R, et al. Advantages of virtual reality in the rehabilitation of balance and gait: systematic review. Neurology 2018;90:1017-25.

19 Lee HS, Park YJ, Park SW. The effects of virtual reality training on function in chronic stroke patients: a systematic review and metaanalysis. Biomed Res Int 2019;2019:1-12.

20 Chan A-W, Tetzlaff JM, Gøtzsche PC, et al. Spirit 2013 explanation and elaboration: guidance for protocols of clinical trials. BMJ 2013;346:e7586.

21 Doğan A, Mengüllüoğlu M, Özgirgin N. Evaluation of the effect of ankle-foot orthosis use on balance and mobility in hemiparetic stroke patients. Disabil Rehabil 2011;33:1433-9.

22 Biering-Sørensen F, Nielsen JB, Klinge K. Spasticity-assessment: a review. Spinal Cord 2006;44:708-22.

23 Folstein MF, Folstein SE, McHugh PR. "Mini-mental state". A practical method for grading the cognitive state of patients for the clinician. J Psychiatr Res 1975;12:189-98.

24 Mehrholz J, Wagner K, Rutte K, et al. Predictive validity and responsiveness of the functional ambulation category in hemiparetic patients after stroke. Arch Phys Med Rehabil 2007;88:1314-9.
25 Brott T, Adams HP, Olinger CP, et al. Measurements of acute cerebral infarction: a clinical examination scale. Stroke 1989;20:864-70.

26 Dean AG, Sullivan KM, Soe MM. OpenEpi: open source epidemiologic statistics for public health, 2013. Available: http:// www.openepi.com/ [Accessed 11 Mar 2019].

27 Lloréns R, Gil-Gómez J-A, Alcañiz M, et al. Improvement in balance using a virtual reality-based stepping exercise: a randomized controlled trial involving individuals with chronic stroke. Clin Rehabil 2015;29:261-8.

28 Dallal GE. Randomization.com, 2013. Available: http://www. randomization.com [Accessed 22 Mar 2019].

29 Miyamoto ST, Lombardi Junior I, Berg KO, et al. Brazilian version of the Berg balance scale. Braz J Med Biol Res 2004;37:1411-21.

30 Zambaldi PA, Costa T, Diniz G, et al. The effect of balance training in a group of community-dwelling elderly women:a pilot study of a specific, non-systematic and short-term approach. Acta Fisiátrica 2016;14:17-24.

31 Duncan PW, Weiner DK, Chandler J, et al. Functional reach: a new clinical measure of balance. J Gerontol 1990;45:M192-7.

32 Silveira KRM, Matas SLA, Perracini MR. Assessment of performance in the functional reach and lateral reach tests in a Brazilian population sample. Rev bras fisioter 2006;10:381-6.

33 Dutra MC, Cabral AL, Carvalho GA. Brazilian version of timed up and go test. Interfaces 2016;3:81-8.

34 Bischoff HA, Stähelin HB, Monsch AU, et al. Identifying a cut-off point for normal mobility: a comparison of the timed 'up and go' test in community-dwelling and institutionalised elderly women. Age Ageing 2003;32:315-20.

35 Duarte M, Freitas SMSF. Revision of posturography based on force plate for balance evaluation. Rev Bras Fisioter 2010;14:183-92.

36 Luft C, Andrade A. EEG and motor learning research. Rev Port Cien Desp 2006;6:106-15.

37 Lam HSP, Lau FWK, Chan GKL, et al. The validity and reliability of a 6-metre timed walk for the functional assessment of patients with stroke. Physiother Theory Pract 2010;26:251-5.

38 Kinsella S, Moran K. Gait pattern categorization of stroke participants with equinus deformity of the foot. Gait Posture 2008;27:144-51.

39 Castro PMMA, Magalhães AMde, Cruz ALC, et al. Testes de equilíbrio e mobilidade funcional na predição e prevenção de riscos de quedas em idosos. Rev Bras Geriatr Gerontol 2015;18:129-40.

40 Puig-Diví A, Escalona-Marfil C, Padullés-Riu JM, et al. Validity and reliability of the Kinovea program in obtaining angles and distances using coordinates in 4 perspectives. PLoS One 2019;14:6.

41 Riberto M, Miyazaki MH, Jucá SS, et al. Validation of the Brazilian version of functional independence. Measure Acta fisiátrica 2016;11:72-6.

42 Lima RCM, Teixeira-Salmela LF, Magalhães LC, et al. Psychometric properties of the Brazilian version of the stroke specific quality of life scale: application of the Rasch model. Braz J Phys Ther 2008;12:149-56.

43 McAuley E, Duncan T, Tammen VV. Psychometric properties of the intrinsic motivation inventory in a competitive sport setting: a confirmatory factor analysis. Res Q Exerc Sport 1989;60:48-58.

44 Borg G, Hassmén P, Lagerström M. Perceived exertion related to heart rate and blood lactate during arm and leg exercise. Eur $J$ Appl Physiol Occup Physiol 1987;56:679-85.

45 Foster C, Florhaug JA, Franklin J, et al. A new approach to monitoring exercise training. J Strength Cond Res 2001;15:109-15.

46 Galvão ML, Gouvêa P, Ocamoto G, et al. Virtual reality effect on upper limb motor function paretic in post stroke. Rev Neurocienc 2015;23:493-8.

47 Allet L, Armand S, de Bie RA, et al. The gait and balance of patients with diabetes can be improved: a randomised controlled trial. Diabetologia 2010;53:458-66.

48 Soares MA, Sacchelli T. Effects of physical therapy on balance of elderly people. Rev Neurocienc 2008;16:97-100.

49 Nascimento LCG, Patrizzi LJ, Oliveira C. Result of four weeks of propreoceptive training in the studied postural balance of elderly. Fisioter Mov 2012;25:325-31.

50 Ribeiro K, Oliveira BS, Ferreira LM, et al. Effectiveness of otolith repositioning maneuvers and vestibular rehabilitation exercises in elderly people with benign paroxysmal positional vertigo: a systematic review. Braz J Otorhinolaryngol 2015;84:104-18.

51 Karasu AU, Batur EB, Karatas GK. Effectiveness of Wii-based rehabilitation in stroke: a randomized controlled study. J Rehabil Med 2018;50:406-12.

52 Hung J-W, Chou C-X, Hsieh Y-W, et al. Randomized comparison trial of balance training by using exergaming and conventional weightshift therapy in patients with chronic stroke. Arch Phys Med Rehabil 2014:95:1629-37. 
53 Agmon M, Perry CK, Phelan E, et al. A pilot study of Wii fit exergames to improve balance in older adults. J Geriatr Phys Ther 2011;34:161-7.

54 Balady GJ, Chaitman B, Driscoll D, et al. Recommendations for cardiovascular screening, staffing, and emergency policies at health/ fitness facilities. Circulation 1998;97:2283-93.

55 Fox SM, Naughton JP, Haskell WL. Physical activity and the prevention of coronary heart disease. Ann Clin Res 1971;3:404-32.

56 Scaglioni-Solano P, Aragón-Vargas LF. Validity and reliability of the Nintendo Wii balance board to assess standing balance and sensory integration in highly functional older adults. Int $J$ Rehabil Res 2014:37:138-43.

57 Hytönen M, Pyykkö I, Aalto H, et al. Postural control and age. Acta Otolaryngol 1993;113:119-22.
58 Grabiner MD, Lundin TM, Feuerbach JW. Converting Chattecx balance system vertical reaction force measurements to center of pressure excursion measurements. Phys Ther 1993;73:316-9.

59 EMOTIV. Emotiv software development kit user manual for release 1.0.0.3. Emotiv Ltd: HongKong, 2011.

60 Oliveira SMS, Medeiros CSP, Pacheco TBF, et al. Electroencephalographic changes using virtual reality program: technical note condensed title: a study using a mobile EEG device. Neurol Res 2018;40:160-5.

61 Lakens D. Calculating and reporting effect sizes to facilitate cumulative science: a practical primer for t-tests and ANOVAs. Front Psychol 2013;4:863.

62 Carvalho APV, Silva V, Grande AJ. Assessment of risk of bias in randomized controlled trials by the Cochrane collaboration tool. Diagn Tratamento 2013;18:38-44. 